\title{
Effect of X-ray Irradiation on Articular Cartilage Mechanical Properties
}

\author{
E. CICEK* \\ Faculty of Sciences and Arts, Mehmet Akif Ersoy University, Burdur, Turkey
}

\begin{abstract}
A load bearing tissue found at the ends of articulating bones, the articular cartilage provides low friction surfaces for efficient movement. Its mechanical properties are determined by the structure and composition of type II collagen, proteoglycans and interstitial fluid. This work investigates the effects of X-ray irradiation, previously shown to affect the biological properties of the articular tissue, on mechanical properties of articular cartilage using polarized light microscope for imaging and compressive modulus test applied to articular cartilage to determine the effects of the ionizing radiation on mechanical properties. According to the test results, the relaxation time is significantly longer in control than X-ray exposed samples, while the force is much higher showing that the X-ray irradiation causes the reduction in the stiffness of articular cartilage.
\end{abstract}

DOI: 10.12693/APhysPolA.129.200

PACS: $87.85 . \mathrm{G}-$

\section{Introduction}

Extracellular matrix of the articular cartilage has many important physiological functions containing determining the mechanical properties of the tissues. Cartilage is a joint lubricating tissue composed primarily of proteoglycans and type II collagen [1], both determining the mechanical properties of articular cartilage and the latter being critically important for the tissue integrity [2].

A fibril volume density distribution effect is lowest on the mechanical behavior of tibial articular cartilage. Any excessive change in the collagen microstructure, as in the case of a compression, will inevitably disrupt the anisotropic environment modifying the mechanical properties of the cartilage [3, 4].

Proteoglycans mainly resist cartilage deformation during static loading $[1,5,6]$. The depth-dependent proteoglycan content affects the cartilage strains substantially. Lowering proteoglycan content in cartilage matrix can thus lessen compressive stiffness, and eventually in the case of continuous growth such a loss can lead towards arthropathies such as osteoarthritis [7, 8].

The ionizing radiation is known to cause a serious acute and persistent reduction in the structural integrity of an exposed skeletal tissue [9]. There is not much data regarding effects of radiation on articular cartilage in the literature, although joint damage has been reported following the cancer treatment or occupational exposures [8]. Most studies on effects of radiation on tissue have concentrated on cells, with less attention paid to the extracellular matrix [10]. It has been found that the radiation causes an active degradation of cartilage, through the decline in proteoglycan synthesis, in the human and

*e-mail: ekrcicek@gmail.com pig chondrocytes [8]. However, to what level and how the radiation affects the matrix environment has not been studied well yet.

The present work aims to investigate how the mechanical properties of articular cartilage change in response to X-radiation exposure in equine articular cartilage using compressive modulus test, which involves loading of the articular cartilage surface via a solid spherical indenter and measuring at the same time the indentation depth $[11,12]$.

\section{Experimental design}

Fresh equine metacarpophalangeal joints were collected from a local abattoir (Potters, Taunton, UK). Cartilage samples taken from specimens displayed no macroscopic degeneration. Full-thickness cartilage plugs $10 \mathrm{~mm}$ in diameter and approximately $1 \mathrm{~mm}$ thick were then excised from dorsal region.

The information about the alignment of collagen fibers was obtained and the dimensions required for calculating compressive stresses were determined from polarized light microscopy images using a Nikon Eclipse E200 PLM.

Irradiations were made using X-rays $(150 \mathrm{kV})$, produced by a Siemens (Germany) X-Ray Equipment (Opti $150 / 30 / 50$ HC-100) located in the medical imaging department of Exeter University in Exeter, UK. Six samples were exposed to X-rays at $4.8 \mathrm{mGy}$.

A stress relaxation test was performed using a cylindrical, plane-ended $3 \mathrm{~mm}$ diameter indenter positioned perpendicular to the superficial zone. Force and displacement were logged using Picolog (Pico Technology Ltd.). $0.45 \mathrm{~kg}$ load cell (RDP Electronics, UK) was used to apply force $(1 \mathrm{mV}=3.393 \mathrm{~N})$. Initially, a force was applied and the cartilage was allowed to come to equilibrium. The cartilage surface was displaced in total $0.5 \mathrm{~mm}$ in ten steps, each step being $50 \mu \mathrm{m}$ [13].

Stress was calculated as load per unit macroscopic sectional field. Strain was calculated with reference to the relaxed length of the sample. 
The control and irradiated samples were immersed in a saline-filled water bath, $\mathrm{pH} 7.4$, thermostated to $25^{\circ} \mathrm{C}$ throughout testing [14]. Eight samples, six irradiated and two identical control samples, were analyzed in total.

\section{Results and discussion}

The relaxation time in control group in our study is longer than in the irradiated group (Fig. 1), as the stress is higher as compared with the irradiated cartilage. The force also is higher in control than the X-ray exposed sample. The differences between control and irradiated group strain increase after 0.3 strains. The maximum stress at 0.48 was measured for control 1 at $0.28 \mathrm{MPa}$, while it is only 0.21 for irradiated sample 3 (Fig. 2). The minimum stress values measured for the irradiated sample 1 is 0.091 , while this value is 0.210 in control 2 . One-way analysis of variance (ANOVA) was used for statistical analysis. A $p$-value less than 0.05 was considered significant. For the stress parameters, $p>0.01$ was observed between the groups $(p=0.286)$. These results reflect that lower compressive stiffness in articular cartilage.

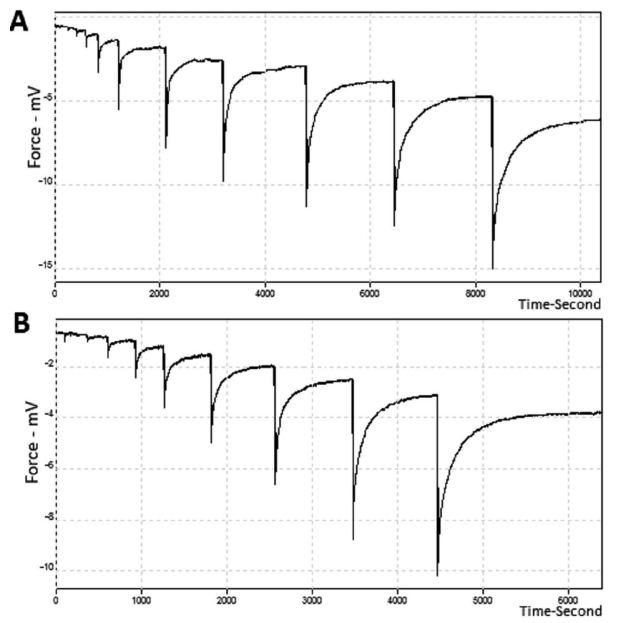

Fig. 1. The graph showing the raw data of compressive module experiment force vs. time $(1 \mathrm{mV}=3.393 \mathrm{~N})$ in control (A) and X-ray exposed (B) samples.

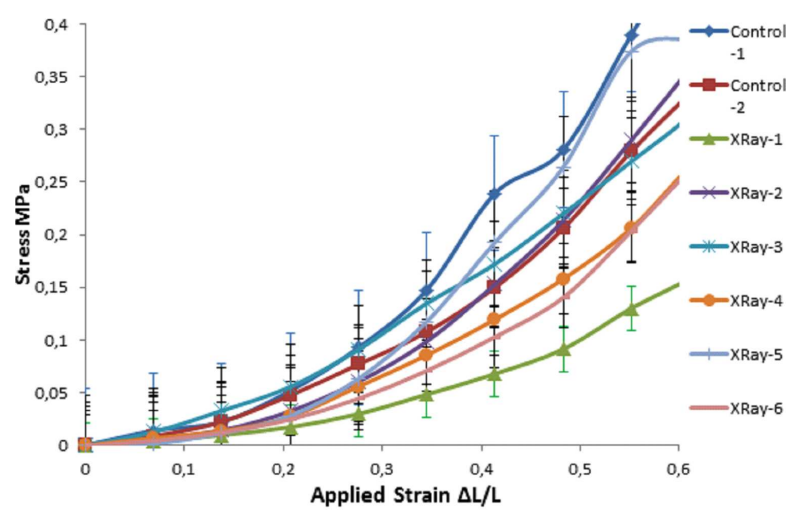

Fig. 2. Representative stress-strain curves for articular cartilage.
The collagen network modulates dynamic compressive stiffness of the articular cartilage tissue, the collagen fibril orientation considerably influences the tissue strains during dynamic and static loading and collagen fibril orientation is more important than the collagen content for the mechanical response of cartilage in loaded knee joint $[1,5,6,15,16]$.

Radiation can alter the cell and tissue function and induce degeneration to normal tissues [17]. Musculoskeletal tissues have been known to be late-responding tissues $[18,19]$. In terms of cell viability, mature articular cartilage is generally considered as radiation resistant comparative to other tissues with higher proliferative capacity $[20,21]$. However, being able to degrade various components of the articular matrix, radiation may induce a functional reduction of articular cartilage health after exposure [8].

Ionizing radiation effects on cartilage has been shown to cause acute degeneration of the cartilage matrix in vitro. Ionizing radiation is known to lower proteoglycan content and compressive stiffness [8, 22-25]. Previous studies display that reactive oxygen radicals induced by ionizing radiation may be responsible for the degradation of the physiologically important glycosaminoglycan hyaluronan [10, 26, 27]. Degradation of the proteoglycans and type II collagen present within the matrix of articular cartilage relates to mechanisms of various enzymes [2]. However, effects on these mechanisms are not sufficiently understood. Exposure to both 2 Gy and 10 Gy doses of ionizing radiation in human and pig ankles resulted in the reduction of proteoglycan biosynthesis, impairment of IGF-1 signaling chondrocytes and induction of active degradation of the articular matrix. Collagen II synthesis after radiation exposure has been shown to reduce in bovine articular chondrocytes. Thus there is evidence on degenerative effect of insistent direct irradiation which may contribute to arthropathies [8, 28].

Radiation response of articular cartilage is inconsistent in very young animal models, although a totalbody irradiation study indicates inducing of clinically relevant degenerative changes in the articular cartilage of immature rats [25]. But articular cartilage from adult humans or large animal species seems to degrade after exposure $[24,29]$.

The increase in compressive modulus with strain reflects the increased contribution of the stiffer underlying cartilage [30]. As the radiation evidently damages cartilage matrix metabolism, a reduction in compressive modulus of the radiation exposed cartilage can be theorized [24].

Joint injury is considered as a late consequence of ionizing radiation exposure [24], although there is not much information regarding the early effects on articular cartilage metabolism or mechanical properties. The effects of radiation on cartilage may be concealed by the considerable delay existing between radiation therapy and joint symptoms [24, 31]. Compressive modulus values for equine dorsal cartilage are similar to previous reported 
values $[8,18,20,21,23]$. Our results show that the lower doses of the ionizing radiation can significantly affect compressive modulus values in equine articular cartilage. However, further studies are needed to understand the effects of the ionizing mechanics of the articular cartilage.

\section{Acknowledgments}

I thank the Scientific and Technological Research Council of Turkey (TUBITAK) BIDEP-2219 for grant and Prof. C. Peter Winlove for hosting him at University of Exeter during his sabbatical. The author is grateful to Dr. Jessica Mansfield, Dr. Ellen Green and Dr. Rachel Palfrey for their assistance.

\section{References}

[1] K.S. Halonen, M.E. Mononen, J.S. Jurvelin, J. Toyras, R.K. Korhonen, J. Biomech. 46, 1184 (2013).

[2] D.J. Leong, X.I. Gu, Y. Li, J.Y. Lee, D.M. Laudier, R.J. Majeska, M.B. Schaffler, L. Cardoso, H.B. Sun, Matrix Biol. 29, 420 (2010).

[3] Y. Xia, H. Alhadlaq, N. Ramakrishnan, A. Bidthanapally, F. Badar, M. Lu, J. Struct. Biol. 164, 88 (2008).

[4] E. Cicek, A. Arıkanoglu, Acta Phys. Pol. A 125, 898 (2014).

[5] V.C. Mow, M.H. Holmes, W.M. Lai, J. Biomech. 17, 377 (1984).

[6] R.K. Korhonen, M.S. Laasanen, J. Toyras, R. Lappalainen, H.J. Helminen, J.S. Jurvelin, J. Biomech. 36, 1373 (2003).

[7] M.B. Goldring, K.B. Marcu, Arthritis Res. Ther. 11, 224 (2009).

[8] J.S. Willey, D.L. Long, K.S. Vanderman, R.F. Loeser, Int. J. Radiat. Biol. 89, 268 (2013).

[9] N.N. Baxter, E.B. Habermann, J.E. Tepper, S.B. Durham, B.A. Virnig, J. Am. Med. Assoc. 294, 2587 (2005).

[10] F. Mohamed, D.A. Bradley, C.P. Winlove, Nucl. Instrum. Methods Phys. Res. A 580, 566 (2007).

[11] D.E. Shepherd, B.B. Seedhom, Proc. Inst. Mech. Eng. $H$ 211, 155 (1997).

[12] D.E. Shepherd, B.B. Seedhom, Rheumatology (Oxford) 38, 124 (1999).
[13] C.F. Chang, G. Ramaswamy, R. Serra, Osteoarthr. Cartilage 20, 152 (2012).

[14] J.S. Bell, J. Christmas, J.C. Mansfield, R.M. Everson, C.P. Winlove, Acta Biomater. 10, 2574 (2014).

[15] D.L. Bader, G.E. Kempson, J. Egan, W. Gilbey, A.J. Barrett, Biochim. Biophys. Acta Gen. Subj. 1116, 147 (1992).

[16] M.S. Laasanen, J. Toyras, R.K. Korhonen, J. Rieppo, S. Saarakkala, M.T. Nieminen, J. Hirvonen, J.S. Jurvelin, J. Biorheol. 40, 133 (2003).

[17] C.N. Coleman, H.B. Stone, J.E. Moulder, T.C. Pellmar, Science 304, 693 (2004).

[18] J.W. Hopewell, Med. Pediatr. Oncol. 41, 208 (2003).

[19] J.S. Willey, E.W. Livingston, M.E. Robbins, J.D. Bourland, L. Tirado-Lee, H. Smith-Sielicki, T.A. Bateman, Bone 46, 101 (2010).

[20] M. Cornelissen, H. Thierens, L.D. Ridder, Scanning Microsc. 10, 833 (1996).

[21] A. Jikko, H. Hiranuma, M. Iwamoto, Y. Kato, Y. Okada, H. Fuchihata, Radiat. Res. 146, 93 (1996).

[22] E. Cicek, M. Yildiz, N. Delibas, S. Bahceli, Spectrosc. Lett. 42, 63 (2009).

[23] M.R. Pritchard, J.A. Horton, L.S. Keenawinna, T.A. Damron, Cells Tissues Organs 192, 240 (2010).

[24] C.A. Lindburg, J.S. Willey, D. Dean, J. Orthop. Res. 31, 1780 (2013).

[25] I.D. Hutchinson, J. Olson, C.A. Lindburg, V. Payne, B. Collins, T.L. Smith, M.T. Munley, K.T. Wheeler, J.S. Willey, Int. J. Radiat. Biol. 90, 821 (2014).

[26] Z. Lurie, T. Offer, A. Russo, A. Samuni, D. Nitzan, Free Radic. Biol. Med. 15, 169 (2003).

[27] E.J. Bates, G.S. Harper, D.A. Lowther, B.N. Preston, Biochem. Int. 8, 629 (1984).

[28] J. Ailland, W.U. Kampen, M. Schunke, J. Trentmann, B. Kurz, Ann. Rheum. Dis. 62, 1054 (2003).

[29] S.T. Hugenberg, S.L. Myers, K.D. Brandt, Arthritis Rheum. 32, 468 (1989).

[30] J. Irianto, G. Ramaswamy, R. Serra, M.M. Knight, J. Biomech. 47, 579 (2014).

[31] K.C. Oeffinger, A.C. Mertens, C.A. Sklar, T. Kawashima, M.M. Hudson, A.T. Meadows, D.L. Friedman, N. Marina, W. Hobbie, N.S. KadanLottick, C.L. Schwartz, W. Leisenring, L.L. Robison, N. Engl. J. Med. 355, 1572 (2006). 